\title{
Different genetic clines in response to temperature across the native and introduced ranges of a global plant invader
}

\author{
Jake M. Alexander ${ }^{1 *}$, Mark van Kleunen ${ }^{2}$, Reto Ghezzi ${ }^{1}$ and Peter J. Edwards ${ }^{1}$ \\ ${ }^{1}$ Institute of Integrative Biology, ETH Zurich, Universitätsstrasse 16, ETH Zentrum CHN, 8092 Zürich, Switzerland; \\ and ${ }^{2}$ Ecology, Department of Biology, University of Konstanz, Universitätsstrasse 10, D-78457 Konstanz, Germany
}

\begin{abstract}
Summary
1. Understanding how non-native plants respond to environmental variation, and the limits to these responses, is important for predicting plant invasiveness. Until now, the extent to which species' climatic limits differ on introduction to a new range has not been experimentally tested. Here, we investigate fitness responses to temperature and low-temperature limits to reproduction of native and introduced populations of the widespread forb Plantago lanceolata.

2. We recorded fitness parameters of $P$. lanceolata accessions collected from nearly complete latitudinal gradients in the species' native and introduced ranges and grown in five common gardens arranged along an elevational gradient in the native range (European Alps). The highest garden was located outside the low-temperature limit of the species.

3. Native populations exhibited clear clinal genetic differentiation along temperature gradients, while any differentiation in introduced populations was much weaker; however, the introduced populations displayed higher average fitness and broad climatic tolerance. Despite these differences, both native and introduced plants failed to set seed beyond the elevational range margin and so shared a similar low-temperature limit to reproduction.

4. Synthesis. Our experimental data support observational studies of niche-limit conservatism in non-native plants, which has important implications for their management. Specifically, it suggests that efforts to predict the extent of an invasion based on knowledge of the native niche are likely to be accurate at the level of the species, even if populations undergo genetic changes or respond differently to climatic gradients in the new range.
\end{abstract}

Key-words: environmental gradient, genetic differentiation, local adaptation, niche dynamics, phenotypic plasticity, plant-climate interactions, plant invasion

\section{Introduction}

Predictions of invasive species spread usually assume that the fundamental climatic niche - defined as the range of climatic conditions within which a species can maintain positive population growth (Grinnell 1917; Hutchinson 1957) - is a species attribute that is conserved in the new geographic region (Peterson 2003; Pearman et al. 2008). In support of this assumption, most niche-modelling studies show that non-native species occupy either a subset of, or the same, niche in the introduced as in the native range (reviewed by Alexander \& Edwards 2010; Peterson 2011). A more restricted distribution in the new range might reflect the potential for further spread or adaptation to a narrower range of climatic conditions. For example, through the globalization of trade, European weeds have been

*Correspondence author. E-mail: jake.alexander@env.ethz.ch introduced to warm regions of the world that in many cases represent a subset of the climatic range that they occupy in their native distribution (di Castri 1989).

Despite this generally consistent picture, niche conservatism is not inevitable, and some recent studies have shown introduced populations to occur in climatic conditions outside those occupied in the native range (e.g. Broennimann et al. 2007; Beaumont et al. 2009). In theory, this could occur either because of evolutionary changes in the species' niche or because of ecological changes - for example, enemy release in the new range (DeWalt, Denslow \& Ickes 2004) - that allow the species to fill a greater portion of its fundamental niche (DeWalt, Denslow \& Ickes 2004; Alexander \& Edwards 2010). Several features of invasions could enable introduced populations to overcome barriers to evolution in the native range (Alexander \& Edwards 2010). For example, the bringing together of genotypes from different parts of the native range 
could lead to greater genetic variation and heterosis, with recombinants responding to novel selection in the new range (Keller \& Taylor 2010; Verhoeven et al. 2011). Both mechanisms could explain why outcrossed individuals of some species display a wider ecological amplitude along environmental gradients than parental lines (Heliyanto et al. 2006; Latta, Gardner \& Johansen-Morris 2007) and why some hybrid species have different habitat preferences from their parents (e.g. Reybould et al. 1991). To predict the potential for future spread, therefore, it is important to know the extent to which niche limits are shared across native and introduced ranges. This is difficult to test experimentally, not least because it is necessary to sample genotypes from sites that represent the climatic extremes experienced by a species across both ranges. Nevertheless, even when this is not possible, investigating the extent to which native and introduced populations differ in their climatic limits along an environmental gradient is a promising but as yet little explored approach (Alexander 2010).

Irrespective of the extent to which climatic niches are conserved following introduction, local adaptation to climatic conditions in different parts of the introduced range appears to be a common phenomenon that contributes to the success of some invasive species. For example, genetically based clines in traits such as size and phenology have been reported along gradients of latitude (Colautti, Maron \& Barrett 2009; Keller et al. 2009; Colautti, Eckert \& Barrett 2010), elevation (Monty \& Mahy 2009; Alexander 2010) and continentality (Leger \& Rice 2007). Nonetheless, such clines are likely to be weaker in the introduced than in the native range; not only have introduced populations had less time to adapt, but genotypes with a broad environmental tolerance may have been favoured under the novel conditions in the introduced range (Richards et al. 2006). Such tolerance might be expressed as greater phenotypic plasticity (e.g. Caño et al. 2008; Williams, Auge \& Maron 2008; Chun 2011; but see van Kleunen \& Fischer 2008) or a greater ability to maintain fitness across different environments (i.e. fitness homeostasis) (Parker, Rodriguez \& Loik 2003; Richards et al. 2006), or a combination of both. Thus, native and introduced populations sampled along similar climatic gradients could display different genetic and phenotypic responses to environmental variation (Colautti, Maron \& Barrett 2009; Keller et al. 2009). Understanding the reasons for these differences, and how introduced plants respond to environmental variation in the new range, is important for predicting invasiveness.

Our first objective in this study was to compare, using a novel experimental set-up, the low-temperature limits to reproduction of native and introduced populations of the perennial herb Plantago lanceolata L. (Sagar \& Harper 1964). We focus on temperature, since it is a key climatic factor affecting the fitness and distribution of plants (Teramura, Antonovics \& Strain 1981; Gaston 2003; Normand et al. 2009) and accounts for a large part of the climatic variation along latitudinal and elevational gradients (Körner 2007; Jump, Mátyás \& Peñuelas 2009). Plantago lanceolata has been primarily introduced to regions of the world that are warmer than most of its native range (Hultén \& Fries 1986; Fig. 1). We therefore hypothesized that introduced populations would show higher low-temperature reproduction limits than native populations, because tolerance of low temperatures would not be expected to affect fitness in introduced regions. Our second objective was to compare patterns of genetic differentiation and

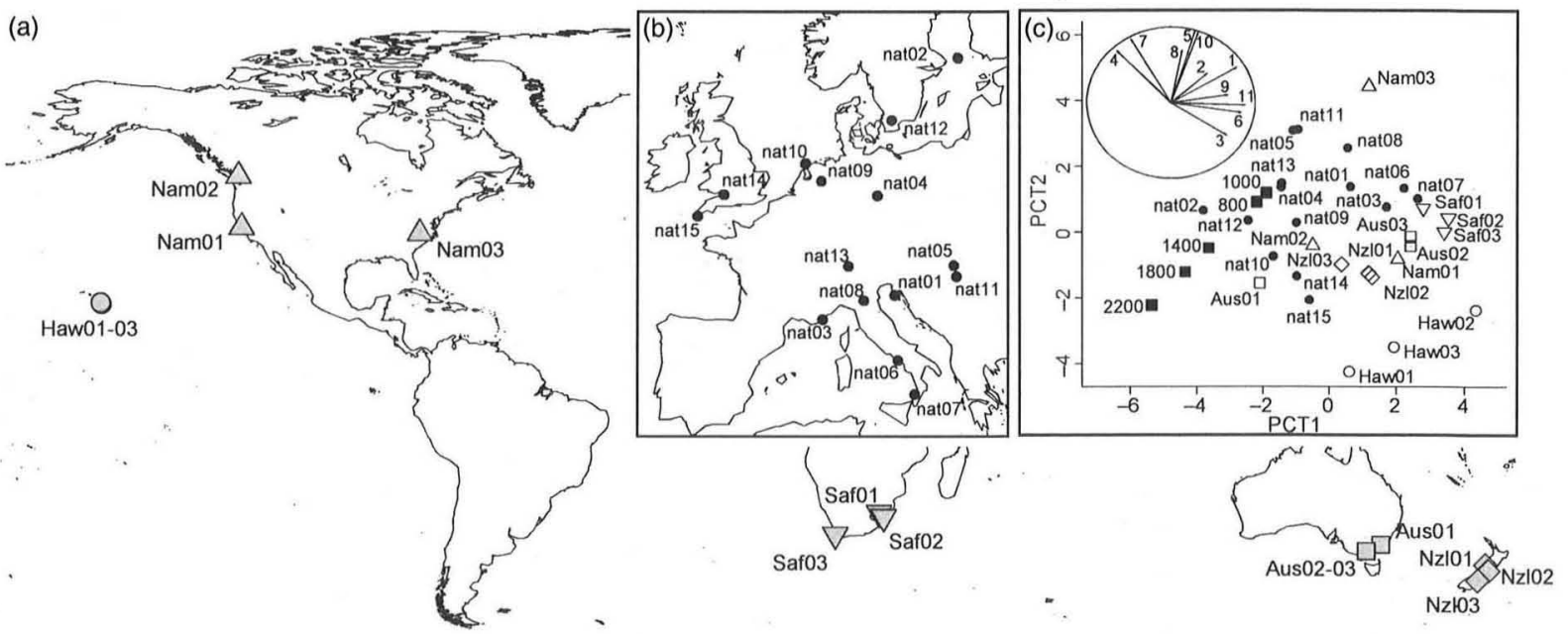

Fig. 1. The locations of the introduced (a) and native (b) populations included in the study and their positions along the first two principal coordinates of a PCA on the 11 temperature variables (c). The five common garden sites (filled squares, indicating $\mathrm{m}$ a.s.l.) are also included in the PCA biplot, but note that the PCA scores used in the mixed effects models were derived from a PCA without sites. Aus, Australia; Haw, Hawaii; Nam, North America; Nzl, New Zealand; Saf, South Africa; nat, native range (Europe). The correlation circle indicates the relative importance of the temperature variables: $1=$ annual mean temperature, $2=$ mean diurnal range, $3=$ isothermality, $4=$ temperature seasonality, $5=$ maximum temperature of warmest month, $6=$ minimum temperature of coldest month, $7=$ temperature annual range, $8=$ mean temperature of wettest quarter, $9=$ mean temperature of driest quarter, $10=$ mean temperature of warmest quarter, $11=$ mean temperature of coldest quarter. 
phenotypic plasticity along temperature gradients in native and introduced populations. Plantago lanceolata is known to show a range of plastic and adaptive responses to environmental variation (Teramura, Antonovics \& Strain 1981; van Tienderen \& van der Toorn 1991; Lacey \& Herr 2000; Joshi et al. 2001; Bischoff et al. 2006) and is therefore an excellent model system to study whether such responses are similar or divergent in different parts of its range. We hypothesized that native populations would show stronger clinal differentiation along a temperature gradient than introduced populations, reflecting the greater time they have had to adapt to local conditions. However, we expected introduced populations either to be phenotypically more plastic or otherwise to be better able to maintain high fitness in response to the range of temperature regimes found along a gradient in elevation.

To test these hypotheses, we collected seed from native and introduced populations spanning the full latitudinal range of $P$. lanceolata from subtropical and Mediterranean to temperate zones. The range in mean annual temperature $\left(\right.$ c. $\left.12.5^{\circ} \mathrm{C}\right)$ at the collection sites therefore captures as far as possible the breadth of temperature conditions experienced by the species. Because we focus on the low-temperature limits of $P$. lanceola$t a$, we grew plants in five common garden sites along an elevational gradient starting below and ending above the maximum elevation at which the species normally occurs in Central Europe, such that the upper two garden sites had cooler climates than any of the collection sites. In any range-wide biogeographical study, collection sites will differ in a number of climatic and non-climatic factors. By transplanting populations along an elevational gradient, we isolated the role of temperature on plant performance from other factors - day-length, for example - that covary along latitudinal gradients. A further advantage of this design is that, even though the study sites are in the native range, no population originates from the study sites, so that comparisons of differences in performance among native and introduced populations (Williams, Auge \& Maron 2008; Colautti, Maron \& Barrett 2009) would be less confounded by any local home-site advantages.

\section{Materials and methods}

\section{POPULATION SAMPLING}

Seeds of $P$. lanceolata were collected by the authors and volunteers from 15 native populations across a wide latitudinal gradient in Europe from southern Italy $\left(38^{\circ} 40^{\prime} \mathrm{N}\right)$ to southern Finland $\left(60^{\circ} 04^{\prime} \mathrm{N}\right)$ and from 15 populations in climatically different parts of its introduced range on three continents (three populations each from Australia, Hawaii, New Zealand, North America and South Africa; Fig. 1, Table S1 in Supporting Information). The native populations represent almost the full latitudinal range of the species in Europe (Hultén $\&$ Fries 1986). For 21 of the 30 populations, seed was collected from three separate plants (i.e. seed families), and for the others, bulked seed collections were made from 5 to 25 plants per population. Seed was collected from plants at least $1 \mathrm{~m}$ apart in natural populations growing in disturbed habitats such as along roadsides.

Climatic conditions at the sample sites were determined from the WORLDCLIM data set (Hijmans et al. 2005), which, despite rather low spatial resolution, has the advantage of ensuring data comparability across all regions. Variability in temperature among the 30 populations was described using a principal components analysis on all 11 temperature variables in WORLDCLIM (see Fig. 1 for a list of variables). The first principal component (hereafter 'PCT1'), which explained $46.5 \%$ of variability in temperature among populations, was primarily a gradient from cool seasonal to warm aseasonal sites; thus, it was negatively correlated with absolute latitude (i.e. latitude irrespective of whether a population was from the northern or southern hemisphere) in both the native range $(r=-0.86)$ and to a lesser extent in the introduced range $(r=-0.53)$. The second principal component ('PCT2') explained a further $34.4 \%$ of variability and represented a gradient from sites with cool oceanic to warm continental climates; it also correlated with latitude, but differently in each range $(r=-0.68$ and 0.30 in the native and introduced ranges, respectively).

\section{EXPERIMENTAL DESIGN}

Five experimental sites were established at 800,1000, 1400, 1800 and $2200 \mathrm{~m}$ above sea level (a.s.l.) on the north side of the Upper Rhein valley in the canton of Grison in eastern Switzerland $\left(46^{\circ} 50^{\prime} \mathrm{N}\right.$, $9^{\circ} 26^{\prime}$ E; Fig. S1), separated by a maximum distance of $21 \mathrm{~km}$. This region is mostly covered with Pinus sylvestris forest, interspersed with settlements, pastures and meadows. The sites were exposed between south and south-east on flat or gently sloping open ground without shading from trees for most of the day. All were located in dry grassland on calcareous bedrock, which is a typical habitat of $P$. lanceolata (Sagar \& Harper 1964). The mean annual temperature (MAT) at the valley bottom was $8.6^{\circ} \mathrm{C}$ (data for the village of Tamins, $626 \mathrm{~m}$ a.s.l.; WORLDCLIM), dropping to $0.3{ }^{\circ} \mathrm{C}$ at the highest field site at $2200 \mathrm{~m}$ a.s.l. The site at $1800 \mathrm{~m}$ a.s.l. (MAT $2.6^{\circ} \mathrm{C}$ ) was near the local low-temperature margin of $P$. lanceolata, and the $2200 \mathrm{~m}$ a.s.l. site beyond it, although populations have been found growing up to $2324 \mathrm{~m}$ a.s.l. (MAT $-0.3^{\circ} \mathrm{C}$ ) in disturbed roadside sites in other regions of Switzerland (A. Halbritter, unpubl. data; Sagar \& Harper 1964). The upper two sites had a colder climate than any of the sample sites where seed was collected (Fig. 1, Table S1).

Three blocks $(1.6 \times 1.5 \mathrm{~m})$ were established at each site by first removing the uppermost $5 \mathrm{~cm}$ of soil containing the roots of the native vegetation, followed by tilling and removal of large roots and stones. In the Alps, the growing season is delayed by $c$. 6 days for every 100-m increase in elevation (Theurillat \& Guisan 2001), and the seeds for each site were therefore sown in succession so that each site was planted with seedlings of the same age. To avoid extending the planting period excessively, however, we chose an interval of 1 week for every $400 \mathrm{~m}$ increase in elevation. Seeds were sown into plug trays (one seed family per cell or one population per cell for bulked samples) containing seed compost (Klasmann-Deilmann, Gross Hesepe, Germany) between 23 April (for the lowest site) and 20 May 2009 (for the highest site). After 2 weeks in a greenhouse in Zurich, Switzerland $\left(47^{\circ} 22^{\prime} \mathrm{N}, 8^{\circ} 32^{\prime} \mathrm{E}, 415 \mathrm{~m}\right.$ a.s.l), seedlings were thinned to one per cell and then moved to a garden in Zurich. After a further 3 weeks, we measured the size of the seedlings as the length of the longest leaf multiplied by the number of leaves, which for adult plants is highly correlated with total biomass $(r=0.80$, d.f. $=34, P<0.001)$. Seedlings were then transplanted directly into the field sites, starting on May 26. Plants were planted into the native soil at each site, and so although we controlled as far as possible for differences in soil conditions, we cannot fully exclude that differences between sites might have contributed to the effects of climate on plant performance. 
In each block, we planted one seedling of every seed family (or three plants per population for bulked seed collections), giving a total of 90 plants per block and 270 plants per site. The seedlings were randomly assigned to positions in a grid with each plant separated by $15 \mathrm{~cm}$. To promote establishment, the seedlings were watered and treated with molluscicide at planting, and growth fleece (Windhager, Thalgau, Austria) was used to protect them for the first week. The sites were protected against livestock with an electric fence.

\section{DATA COLLECTION}

Following previous authors (e.g. van Tienderen 1992; Lacey \& Herr 2000; Joshi et al. 2001), various parameters related to fitness were measured on all plants during two growing seasons. In the first season, we recorded whether or not a plant was flowering, the number of flowering spikes produced at the onset of flowering and survival to the end of the season. In the second season, we recorded overwinter survival, survival to the end of the season, whether or not a plant flowered or set seed, and the maximum number of flowering spikes. Although the number of flowering spikes correlates with reproductive fitness (Lacey \& Herr 2000), not all spikes reach maturity and so flowering traits may overestimate final seed production (van Tienderen 1992). The records in the first year were made during weekly visits to the sites, while in the second year, they were made at the start (14 April 2010), middle (20 July 2010) and end of the season (15 September 2010). Flowering had barely begun at the highest site in July 2010, and by September 2010, most plants had senesced in sites below $1800 \mathrm{~m}$ a.s.l. The number of flowering spikes in the second season was therefore recorded as the maximum across the sampling dates for analysis. In a few cases, seed may have been shed at the sites below $2200 \mathrm{~m}$ a.s.l. before the spikes were inspected, and data on the probability that plants set seed at these sites should be regarded as conservative.

\section{STATISTICAL ANALYSES}

All analyses were performed using the lme4 package (Bates, Maechler \& Bolker 2011) in R (R Development Core Team 2010). Generalized linear mixed effects models (GLMMs) were used to fit a full model containing the fixed effects of common garden site (hereafter 'site'), range of origin (native or introduced), the first principal component of temperature variables for each population (PCT1), and their two- and three-way interactions. The response variables were the probabilities of flowering in each season and setting seed in the second season (excluding dead plants), the number of flowering spikes in each season (excluding non-flowering plants), and the probabilities of surviving until the end of the first season and through the winter. GLMMs were fitted using the Laplace method with a binomial family or Poisson family for the number of flowering spikes (Bolker $e t$ al. 2009). Due to very low numbers of flowering individuals, the highest site (2200 m a.s.l.) in the first season and the lowest site $(800 \mathrm{~m}$ a.s.l.) in the second season were excluded from analysis of flowering and number of flowering spikes. At the lowest site, survival into the second season was slightly less likely for plants that had flowered in the first season $(r=-0.12$, d.f. $=268, P=0.045)$, although there were either positive or non-significant relationships between performance across seasons at the other sites. For each response, eight reduced models were fitted with the same main effects (site, range and PCT1) but with different combinations of interactions. All models also contained population and block as random effects to account for the nested structure of observations, and the initial size of individuals as a covariate in the fixed model to control for potential maternal effects on early seedling performance. A negative binomial distribution was used to account for over-dispersion in the number of flowering spikes in the second season. Qualitatively similar results were obtained by fitting linear mixed models to log-transformed count data.

Initially, we tested for differences in plasticity among populations in response to the different sites. For each response, we used Akaike Information Criterion, with a correction for small sample size (AICc) that becomes less important at larger sample sizes (Bolker et al. 2009), to compare a model containing the interaction of population and site as random effects with a simpler model containing only populations. The simpler model performed best in all cases (lowest AICc), and so subsequent analyses were performed with models containing only random intercepts for different populations. Next, the nine models differing in their fixed effects were compared using AICc. The minimum adequate model (MAM) was selected as the model with the lowest AICc given the set of competing models. Support for the MAM is lent by the difference in AICc scores $\left(\Delta_{i}\right)$ between it and poorer models, with $\Delta_{i}>2$ typically indicating strong support (Burnham \& Anderson 2002). Additionally, Akaike weights ( $\left.w_{i}\right)$ were calculated for every model with $\Delta_{i}<10$, which normalize the relative likelihood of each model and can be interpreted as the probability that model $i$ is the best given the set of candidate models (Burnham \& Anderson 2002). $w_{i}$ can be summed across a subset of models to give the relative support for that subset, and similarly, the relative importance of an individual variable can be calculated as the sum of $w_{i}$ over all the models in which it appears (Burnham \& Anderson 2002). If the MAM was the simplest model (main effects only), model selection was continued using an expanded set of reduced models with different combinations of main effects and no interactions, including a null model with initial size as the only fixed effect. Interactions involving range were further explored by fitting data for native and introduced plants separately. A full model containing PCT1, site and their interaction was compared with the four possible simpler models involving these variables. Similarly, differences in traits and their reaction norms across sites among the five regions of introduction were tested by comparing a full model containing region, site and their interaction with the four possible simpler models. Finally, the analysis was repeated as above but including the second principal component of temperature variables (PCT2), or absolute latitude, of each population in the models instead of PCT1. Where PCT2 was included in the MAM for a given trait, additional models were fitted to data for native and introduced plants separately.

\section{Results}

\section{DIFFERENT RESPONSES OF PLANTS FROM THE NATIVE AND INTRODUCED RANGES}

Plants of native and introduced origin differed consistently in the degree to which they were clinally differentiated along the temperature gradient (range $\times$ PCT1 interaction, Table 1, Table S2). Although the support for the MAM was relatively weak for three traits (competing models within $\Delta_{i}=2$ of the MAM, $w_{i}$ of the MAM $<0.585$; Table 1), support for the range $\times$ PCT1 interaction was always strong (sum of $w_{i}$ across all models containing this interaction $>0.658$; Table 1 ). In models fitted to data from the native range only, plants from cooler source areas had a higher probability of flowering in both seasons, a higher probability of setting seed, higher overwinter survival and a greater number of flowering spikes in the second season $\left(w_{i}>0.665\right.$; Table 2; Fig. 2$)$, with these 
Table 1. Parameters and Akaike weights $\left(w_{i}\right)$ of the minimum adequate models (MAM) of fitness traits in Plantago lanceolata selected using AICc. The sum of Akaike weights across all models in which a particular parameter was present for a given trait is shown in parentheses. See Table S2 for the full results of model selection

\begin{tabular}{lll}
\hline Response & MAM $w_{i}$ & Parameters* \\
\hline No. of flowering spikes in season 1 & 0.317 & Site $(1.00)+$ range $(0.549)$ \\
No. of flowering spikes in season 2 & 0.320 & Range $\times$ PCT1 $(0.658)+$ site $\times$ PCT1 $(0.579)$ \\
Flowered in season 1 & 0.359 & Range $\times$ PCT1 $(0.977)+$ site $\times$ range $(0.523)$ \\
Flowered in season 2 & 0.763 & Range $\times$ PCT1 $(0.958)+$ site $(1.00)$ \\
Set seed in season 2 & 0.828 & Range $\times$ PCT1 $(0.965)+$ site $(1.00)$ \\
Survival to end of season 1 & 0.419 & Site $(1.00)$ \\
Overwinter survival & 0.585 & Range $\times$ PCT1 $(0.980)+$ site $(1.00)$ \\
\hline
\end{tabular}

*All models also contained initial size as a covariate and the random effects of population and block. Parameters included in interactions were also present as main effects.

Table 2. Results of model selection for models fitted to plants from the native and introduced ranges separately. Shown are performance traits for which there was support for an interaction of range $\times$ PCT1 in the full analysis (Table 1). Included are model parameters (S, site), the difference in AICc score $\left(\Delta_{i}\right)$ from the minimum adequate model and the Akaike weights $\left(w_{i}\right)$, for all models with $\Delta_{i}<5$

\begin{tabular}{|c|c|c|c|c|c|c|}
\hline \multirow[b]{2}{*}{ Response } & \multicolumn{3}{|c|}{ Native range } & \multicolumn{3}{|c|}{ Introduced range } \\
\hline & Model* & $\Delta_{i}$ & $w_{i}$ & Model* & $\Delta_{i}$ & $w_{i}$ \\
\hline \multirow[t]{3}{*}{ No. of flowering spikes in season 2} & $\mathrm{~S}+\mathrm{PCT} 1$ & 0.00 & 0.894 & S & 0.00 & 0.512 \\
\hline & $\mathrm{S} \times \mathrm{PCT} 1$ & 4.46 & 0.096 & $\mathrm{~S}+\mathrm{PCT} 1$ & 1.06 & 0.301 \\
\hline & & & & $\mathrm{S} \times \mathrm{PCT} 1$ & 2.02 & 0.187 \\
\hline \multirow[t]{3}{*}{ Flowered in season 1} & $\mathrm{~S}+\mathrm{PCT} 1$ & 0.00 & 0.891 & $\mathrm{~S}$ & 0.00 & 0.379 \\
\hline & & & & $\mathrm{S}+\mathrm{PCT} 1$ & 0.14 & 0.353 \\
\hline & & & & $\mathrm{S} \times \mathrm{PCT} 1$ & 0.69 & 0.268 \\
\hline \multirow[t]{2}{*}{ Flowered in season 2} & $\mathrm{~S}+\mathrm{PCT} 1$ & 0.00 & 0.729 & $\mathrm{~S}$ & 0.00 & 0.716 \\
\hline & PCT1 & 2.46 & 0.213 & $\mathrm{~S}+\mathrm{PCT} 1$ & 2.07 & 0.255 \\
\hline \multirow[t]{3}{*}{ Set seed in season 2} & $\mathrm{~S}+\mathrm{PCT} 1$ & 0.00 & 0.875 & $\mathrm{~S}$ & 0.00 & 0.660 \\
\hline & & & & $\mathrm{S}+\mathrm{PCT} 1$ & 2.00 & 0.242 \\
\hline & & & & $\mathrm{S} \times \mathrm{PCT} 1$ & 3.81 & 0.098 \\
\hline \multirow[t]{2}{*}{ Overwinter survival } & $\mathrm{S}+\mathrm{PCT} 1$ & 0.00 & 0.665 & $\mathrm{~S}+\mathrm{PCT} \mathbf{1}$ & 0.00 & 0.930 \\
\hline & $\mathrm{S} \times \mathrm{PCT} 1$ & 1.37 & 0.335 & & & \\
\hline
\end{tabular}

*All models also contained initial size as a covariate and the random effects of population and block. Parameters included in interactions were also present as main effects.

relationships being generally constant across sites (i.e. little support for PCT1 $\times$ site interactions; Table 2). In contrast, the performance of introduced plants - measured as the flowering spike number in the second season, probability of flowering in each season and of setting seed in the second season - did not depend on the climate from which they were sampled (difference from the MAM in AICc scores for models containing PCT1 in addition to site $=0.14-2.07$ ). However, introduced plants were also more likely to survive over winter if they originated from cooler climates (Table 2; Fig. 2b). Clines in overwinter survival differed between native and introduced populations (range $\times$ PCT1, Table 1). In models fitted to each range separately, the decline in overwinter survival with increasing PCT1 was steeper in the native than in the introduced range (Fig. 2b).

Populations were also differentiated along the second principal component of temperature variables (PCT2) for five of the fitness traits (Table 3; Table S3). When these traits were mod- elled using data from the native and introduced ranges separately, there was strong evidence for clines in the native range for survival to the end of the first season and the probability of setting seed in the second season ( $w_{i}$ for model containing PCT2 in addition to site $>0.78$; Table 3 ), but only weak evidence in the introduced range for clines in the probability of flowering in the second season $\left(w_{i}=0.473\right)$. However, in all cases, the performance was greatest for plants from cooler more oceanic climates in the high elevation sites at and above $1800 \mathrm{~m}$ and greatest for plants from warmer more continental climates in the lower elevation sites (interaction site $\times$ PCT2, Table 3; Fig. 3).

On average, introduced populations performed better than native populations. In particular, they produced $12 \%$ and $16 \%$ more flowering spikes in the first and second seasons, respectively, and were 2.8 times more likely to flower in the first season (Fig. 4). Although differences between native and introduced plants were less pronounced in the second season, 

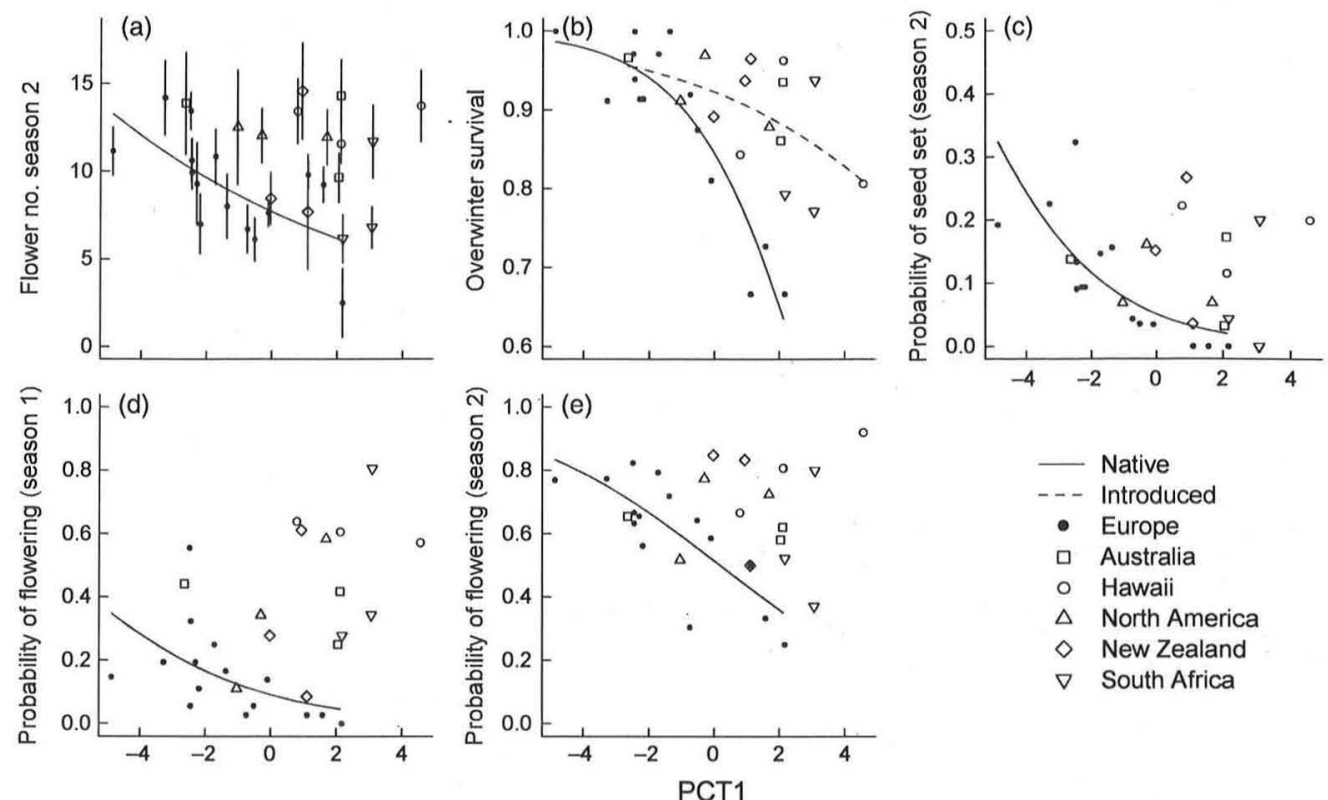

Fig. 2. The relationship between fitness traits (population means across sites; bars in (a) are standard error) and the first principal component of temperature variables (PCT1) for populations from the native range and different regions of introduction. Note that higher PCT1 values represent warmer and less seasonal climatic conditions. Only shown are traits that had significant effects of PCT1 in mixed effects models (Table 1), and trend lines (fitted values from univariate models involving a given trait and PCT1) are shown for significant effects of PCT1 in models fitted to data from the native and introduced ranges separately.

Table 3. Results of model selection for models fitted to plants from the native and introduced ranges separately. Shown are performance traits for which there was support for an effect of PCT2 in the full analysis (Table S3). Included are model parameters (S, site), the difference in AICc score $\left(\Delta_{i}\right)$ from the minimum adequate model and the Akaike weights $\left(w_{i}\right)$, for all models with $\Delta_{i}<5$

\begin{tabular}{|c|c|c|c|c|c|c|}
\hline \multirow[b]{2}{*}{ Response } & \multicolumn{3}{|l|}{ Native range } & \multicolumn{3}{|c|}{ Introduced range } \\
\hline & Model* & $\Delta_{i}$ & $w_{i}$ & Model* & $\Delta_{i}$ & $w_{i}$ \\
\hline \multirow[t]{2}{*}{ No. of flowering spikes in season 2} & $\mathrm{~S}$ & 0.00 & 0.681 & $\mathrm{~S}$ & 0.00 & 0.615 \\
\hline & $\mathrm{S}+\mathrm{PCT} 2$ & 2.05 & 0.244 & $\mathrm{~S}+\mathrm{PCT} 2$ & 1.62 & 0.273 \\
\hline . & $\mathrm{S} \times \mathrm{PCT} 2$ & 4.40 & 0.075 & $\mathrm{~S} \times \mathrm{PCT} 2$ & 3.41 & 0.112 \\
\hline \multirow{2}{*}{ Flowered in season 1} & $\mathrm{~S}$ & 0.00 & 0.713 & $\mathrm{~S}$ & 0.00 & 0.644 \\
\hline & $\mathrm{S}+\mathrm{PCT} 2$ & 2.04 & 0.257 & $\mathrm{~S}+\mathrm{PCT} 2$ & 1.30 & 0.336 \\
\hline \multirow[t]{3}{*}{ Flowered in season 2} & $\mathrm{~S}$ & 0.00 & 0.651 & $\mathrm{~S} \times \mathrm{PCT} 2$ & 0.00 & 0.473 \\
\hline & $\mathrm{S}+\mathrm{PCT} 2$ & 1.87 & 0.256 & $\mathrm{~S}$ & 0.45 & 0.378 \\
\hline & & & & $\mathrm{S}+\mathrm{PCT} 2$ & 2.40 & 0.143 \\
\hline \multirow[t]{3}{*}{ Set seed in season 2} & $\mathrm{~S} \times \mathrm{PCT} 2$ & 0.00 & 0.780 & $\mathrm{~S}$ & 0.00 & 0.661 \\
\hline & $\mathrm{S}$ & 3.85 & 0.114 & $\mathrm{~S}+\mathrm{PCT} 2$ & 1.49 & 0.314 \\
\hline & $\mathrm{S}+\mathrm{PCT} 2$ & 4.27 & 0.092 & & & \\
\hline \multirow[t]{2}{*}{ Survival to end of season 1} & $\mathrm{~S} \times \mathrm{PCT} 2$ & 0.00 & 0.941 & $\mathrm{~S}$ & 0.00 & 0.596 \\
\hline & & & & $\mathrm{S}+\mathrm{PCT} 2$ & 0.89 & 0.381 \\
\hline
\end{tabular}

*All models also contained initial size as a covariate and the random effects of population and block. Parameters included in interactions were also present as main effects.

introduced plants remained $8 \%$ more likely to flower and $9 \%$ more likely to set seed. This superiority in performance of introduced plants was also apparent when comparing the performance, for example overwinter survival, of native and introduced plants from collection sites with similar temperatures (Fig. 2). Despite strong differences in the fitness parameters across sites, there was little evidence of any differences in plasticity or fitness homeostasis between the native and introduced ranges; the only exception was that the proportion of plants flowering in the first season varied more across sites for the introduced populations (Table 1, Fig. 4). Populations also did not differ in their plasticity across sites (difference in AICc for 

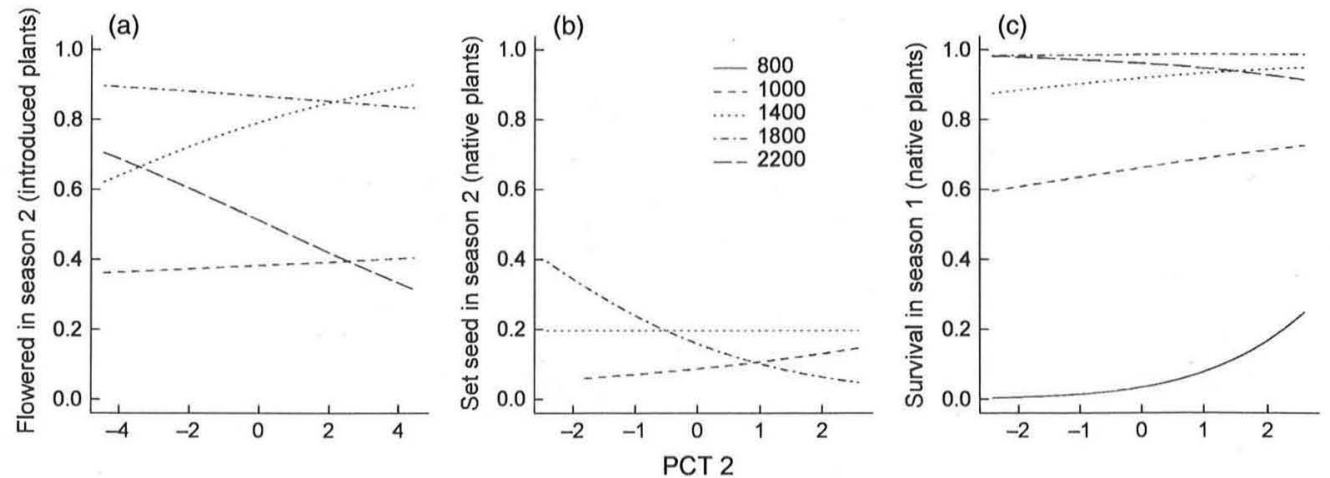

Fig. 3. The relationship between fitness traits and the second principal component of temperature variables (PCT2) in experimental sites at different elevations (800-2200 m a.s.l.) for populations from either the introduced (a) or native (b, c) ranges. Note that higher PCT2 values represent warmer more continental climatic conditions. Only traits for which the site $\times$ PCT2 interaction was supported by mixed effects models fitted to data from the two ranges separately (Table 3) are shown.

models containing population $\times$ site random effects $>13$; Fig. S2), although the relatively low replication of populations within sites might have reduced our power to detect these effects. Furthermore, there was no evidence for differences in any fitness parameter between plants from the different regions of introduction, nor in their norms of reaction for fitness traits across the elevational gradient; for all traits, the MAM contained only the effect of site $\left(w_{i}=0.559-0.986\right)$.

\section{VARIATION IN FITNESS PARAMETERS AND RANGE LIMITS ALONG THE ELEVATIONAL GRADIENT}

In the first season, both the probability of flowering and the mean number of flowering spikes generally declined with elevation, with only two plants flowering at $2200 \mathrm{~m}$ a.s.l. (Fig. 4). However, plants were much more likely to survive to the end of the first season at higher elevations, with a peak at $1800 \mathrm{~m}$ a.s.l. Similarly, overwinter survival was greatest at $1800 \mathrm{~m}$ a.s.l., and although lower beyond the range margin at $2200 \mathrm{~m}$ a.s.l., it was lowest below $1400 \mathrm{~m}$ a.s.l. (Fig. 4).

Those plants that survived into the second season produced many more flowering spikes and were more likely to flower at intermediate elevations, again with a peak at $1800 \mathrm{~m}$ a.s.l. Even at the highest site (2200 $\mathrm{m}$ a.s.l.), half of all plants flowered, although they produced fewer flowering spikes than at other sites. The proportion of plants flowering in the highest site was especially high among the populations from Hawaii and New Zealand, but in general, there was no difference between native and introduced ranges in the decline in performance at the highest site (Fig. 4). The probability of seed set was generally low but followed the same trend as flowering, with a peak at 1400-1800 m a.s.l. (Fig. 4). The proportion of plants that set seed declined from $33 \%$ at $1000 \mathrm{~m}$ a.s.l. to $26 \%$ at $1400 \mathrm{~m}$ a.s.l. and $19 \%$ at $1800 \mathrm{~m}$ a.s.l., but no seed was produced at $2200 \mathrm{~m}$ a.s.l. Since these proportions are similar to, or slightly higher than, those reported in a previous study (van Tienderen 1992), we regard as minimal any error due to seeds being shed before the spikes were examined. Only two plants died during the second season at the highest two sites, while $40 \%$ of the remaining plants died at $1000 \mathrm{~m}$ a.s.l. and $69 \%$ of plants at $1400 \mathrm{~m}$ a.s.l.

\section{Discussion}

RESPONSES TO TEMPERATURE VARIATION OF PLANTS FROM THE NATIVE AND INTRODUCED RANGES

We found differences in the performance of native and introduced populations of $P$. lanceolata collected along temperature gradients, with clear evidence for clinal differentiation among native populations. This was most pronounced along PCT1, where native plants from cooler and more seasonal climates at high latitudes performed better than native plants from warmer climates. Presumably, these plants were at an advantage because the climates of the common gardens were cooler than those of all but three native populations. A similar result - with greater fitness of plants from cooler source regions - was also recorded for Lactuca serriola growing in the same experimental sites (Alexander 2010). Although native populations were much less differentiated along PCT2, plants from cooler more oceanic climates were also more likely to set seed and survive in the first season, but only in the high elevation sites, while the opposite was true in the lower elevation sites. Together, these patterns are consistent with the interpretation that $P$. lanceolata is locally adapted to temperature conditions across its native range. In support of this, native $P$. lanceolata populations are known to be adapted to different regions or habitats (van Tienderen \& van der Toorn 1991; Joshi et al. 2001; Bischoff et al. 2006), and clinal genetic differentiation along latitudinal gradients is also widespread in other species (Colautti, Maron \& Barrett 2009). Genetic differentiation therefore appears to be a common phenomenon in the native range of species.

In contrast, there was much less evidence for clinal differentiation with respect to temperature in the introduced range. One reason could be that some other factor-perhaps precipitation - is a more important selection pressure affecting these populations, and we therefore re-analysed the data using the 

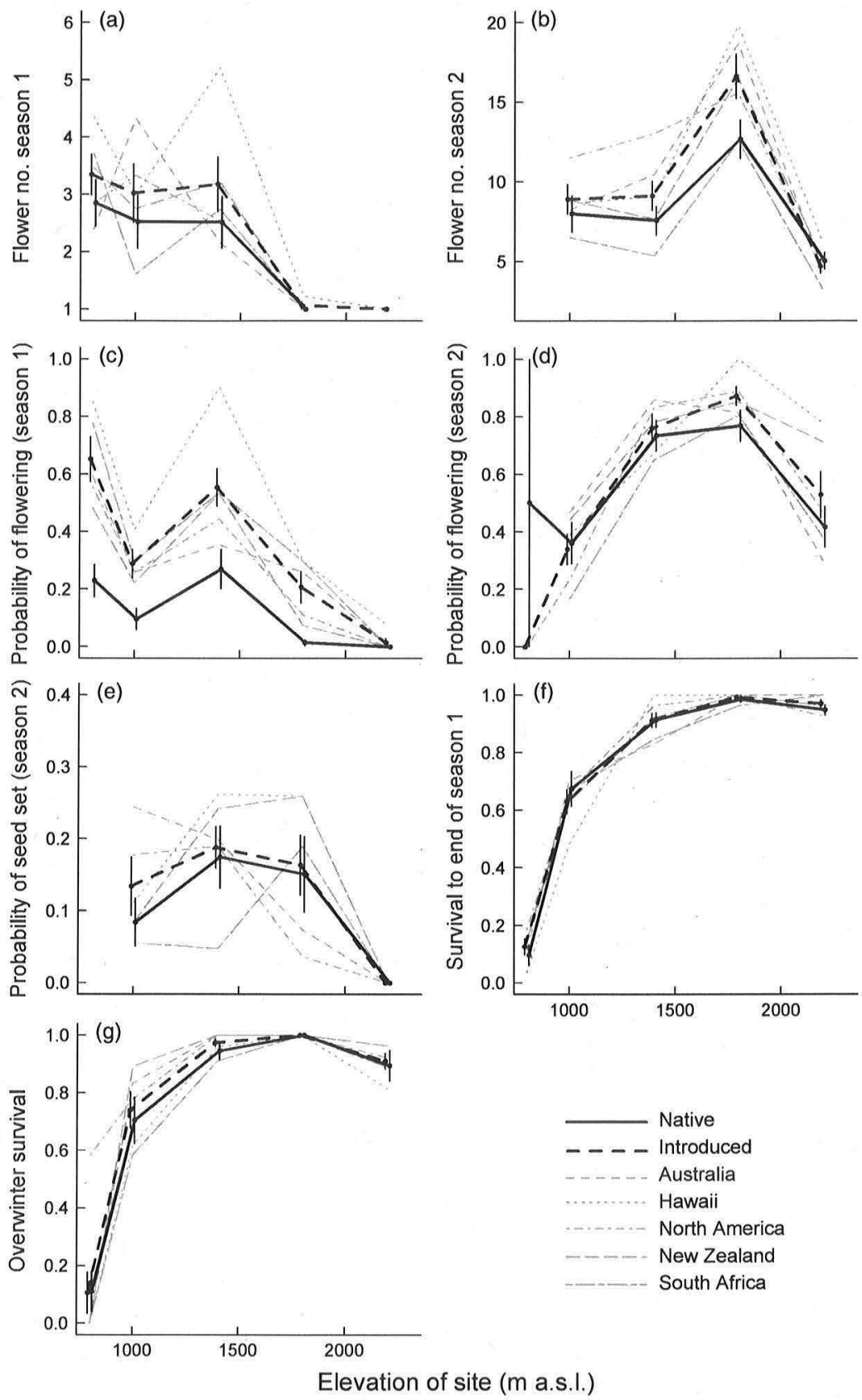

Fig. 4. Reaction norms for fitness parameters across an elevational gradient for native and introduced populations of Plantago lanceolata. The data are means \pm standard error at each site, which have been staggered for clarity. The reaction norms for each individual region of introduction are shown in grey, but error bars have been excluded for clarity.

first axis of a PCA on the eight WORLDCLIM precipitation variables. However, this analysis provided almost no support for clinal variation (Table S3). A second possibility is that by transplanting plants from latitudinal gradients along an elevational gradient, we decoupled temperature and photoperiod as potential environmental cues affecting development and performance (Keller \& Körner 2003; Griffith \&. Watson 2005); this could have affected our comparison of native and introduced populations if they differed in their responses to these cues. However, this explanation seems unlikely because we observed no consistent differences in phenology among populations in the first season. Furthermore, clines in response to factors other than temperature that covary with latitude, such as photoperiod, might have been obscured in the introduced range by the lower correlation of PCT1 and latitude. However, qualitatively similar results were obtained when models were fitted using latitude instead of PCT1. Thus, we conclude that introduced populations of $P$. lanceolata are at best weakly differentiated along climatic gradients, a conclusion supported by the lack of consistent differences in performance among regions. It could be that the period since $P$. lanceolata was first globally dispersed by Europeans has been too short for evolution to occur in response to climatic variation, although this does not appear to have prevented genetic differentiation in other species (reviewed by Colautti, Maron \& Barrett 2009). 
Contrary to our hypothesis, there was little evidence for greater phenotypic plasticity or fitness homeostasis in introduced populations of $P$. lanceolata. Although introduced plants performed on average better than native plants, their greater reproductive potential translated into only slightly higher seed set in the second season. Similar increased fitness has been observed in introduced populations of other species (reviewed by Bossdorf et al. 2005; Colautti, Maron \& Barrett 2009), many of which have exhibited traits associated with greater 'weediness' or opportunistic behaviour, such as the earlier flowering and greater flowering spike production reported here (Baker 1974; Blair \& Wolfe 2004; Keller \& Taylor 2008). However, we also recorded greater overwinter survival, suggesting that introduced plants of $P$. lanceolata have a greater environmental tolerance as well. Furthermore, the superior performance of introduced plants, also for seed set, was most evident when populations originating from regions with a similar climate were compared (and therefore not confounded by environmental gradients; Colautti, Maron \& Barrett 2009). In particular, fitness was relatively greater for introduced plants from warmer regions. There could be several non-mutually exclusive explanations for these patterns, including post-introduction evolution (e.g. Verhoeven et al. 2011) or a founder effect caused by the spread of a particular 'general purpose genotype' or a genotype that is by chance adapted to the conditions in the common gardens, such as from northern Europe, throughout the introduced range (Dlugosch \& Parker 2008; Keller \& Taylor 2008). Molecular evidence (e.g. Keller \& Taylor 2008) and experimental crosses (e.g. Wolfe, Blair \& Penna 2007) would be needed to distinguish between these hypotheses.

\section{LOW-TEMPERATURE LIMITS TO REPRODUCTION ACROSS RANGES}

Despite the different responses to environmental variation, we found that both native and introduced plants reached low-temperature limits to reproduction between 1800 and $2200 \mathrm{~m}$ a.s.l., an elevational difference corresponding to a mean temperature difference of $1.75{ }^{\circ} \mathrm{C}$ over the course of the study. Although most plants survived and many were able to flower in the second season, none was observed to set seed in the highest common garden. The reductions in other fitness traits at $2200 \mathrm{~m}$ a.s.l. were also not different between ranges. From our data, we cannot say why seeds failed to set at the cold-range margin, but we can exclude the possibility that plants shed seed without us observing it, because the plants at $2200 \mathrm{~m}$ a.s.l. were not senescent when we recorded them at the end of the season as they sometimes were at lower sites. Probably, the reasons are similar to those for other plant species (Gaston 2003). For example, Tilia cordata fails to set seed at its northern range margin because pollen tubes grow too slowly to allow fertilization (Pigott \& Huntley 1981), or because the onset of winter cuts short the development of the embryo or endosperm (Pigott 1981). Whatever the explanation, our observations suggest that the processes constraining reproduction at low temperatures are similar in both ranges, irrespective of the fact that the climate of the introduced regions is on average warmer. If so, this would be consistent with many species distribution models showing niches to be conserved in the introduced range (reviewed by Alexander \& Edwards 2010; Peterson 2011). However, the warm-temperature or other climatic limits of this species might differ more between ranges, especially given the presence of populations in warm regions outside of the native temperature range sampled in this study.

\section{Conclusions}

The finding that native and introduced $P$. lanceolata plants have similar low-temperature limits for reproduction has implications for invasive species management. If the climatic niches of most species are indeed conserved, then any rapid adaptive changes in introduced populations must be considered within the context of the overall niche of the species. Thus, adaptation to combinations of climatic variables that are within the climatic niche in the native range might occur frequently (Colautti, Maron \& Barrett 2009), while adaptive shifts to climatic conditions outside of this niche space would be rare. This implies that efforts to predict the extent of an invasion based upon knowledge of the native niche are likely to be accurate at the level of the species (Peterson 2003), even if different native populations occupy different subsets of the overall niche space. However, other potentially adaptive responses such as the increased reproductive performance observed in $P$. lanceolata might be harder to predict but still have significant impacts in invaded communities. Although not explicitly tested in this study, our data suggest that in such cases, local adaptation to climatic conditions might not be a prerequisite for improved performance in non-native genotypes.

\section{Acknowledgements}

We are very grateful to Jean-Francois Berger, Maarten Christenhusz, Salvatore Cozzolino, Gabi Jakobs, S. Kritzinger-Klopper, Elizabeth Lacey, Anna-Liisa Laine, Keith McDougall, Maria Domenica Moccia, James Rodger, Thomas Strobl, Torbjörn Tyler and Neville Walsh for collecting seeds, to Jörg Leuenberger, Tim Seipel, Aud Halbritter, Sebastian Keller and Josephine Haase for assistance in the field, and to Jonathan Levine, the Editor and two anonymous reviewers for valuable comments on the manuscript. J.M.A. was funded by CCES through the BioChange project (0-21214-07).

\section{References}

Alexander, J.M. (2010) Genetic differences in the elevational limits of native and introduced Lactuca serriola populations. Journal of Biogeography, 37, $1951-1961$

Alexander, J.M. \& Edwards, P.J. (2010) Limits to the niche and range margins of alien species. Oikos, 119, 1377-1386.

Baker, H.G. (1974) The evolution of weeds. Anmual Review of Ecology and Systematics, 5, 1-24.

Bates, D., Maechler, M. \& Bolker, B. (2011) Ime4: Linear Mixed-Effects Models using S4 Classes. R package version, 999375-38, http://CRAN. R-project.org/package $=$ lme 4 .

Beaumont, L.J., Gallagher, R.V., Downey, P.O., Thuiller, W., Leishman, M.R. \& Hughes, L. (2009) Modelling the impact of Hieracium spp. on protected areas in Australia under future climates. Ecography, 32, 757-764.

Bischoff, A., Crémieux, L., Smilauerova, M., Lawson, C.S., Mortimer, S.R., Dolezal, J. et al. (2006) Detecting local adaptation in widespread grassland 
species - the importance of scale and local plant community. Journal of Ecology, 94, 1130-1142.

Blair, A.C. \& Wolfe, L.M. (2004) The evolution of an invasive plant: an experimental study with Silene latifolia. Ecology, 85, 3035-3042.

Bolker, B.M., Brooks, M.E., Clark, C.J., Geange, S.W., Poulsen, J.R., Stevens, M.H.H. \& White, J.-S.S. (2009) Generalized linear mixed models: a practical guide for ecology and evolution. Trends in Ecology \& Evolution, 24, 127-135.

Bossdorf, O., Auge, H., Lafuma, L., Rogers, W.E., Siemann, E. \& Prati, D. (2005) Phenotypic and genetic differentiation between native and introduced plant populations. Oecologia, 144, 1-11.

Broennimann, O., Treier, U.A., Müller-Schärer, H., Thuiller, W., Peterson, A.T. \& Guisan, A. (2007) Evidence of climatic niche shift during biological invasion. Ecological Letters, 10, 701-709.

Burnham, K.P. \& Anderson, D.R. (2002) Model Selection and Multimodel Inference : A Practical Information-Theoretic Approach. Springer, New York, NY.

Caño, L., Escarré, J., Fleck, I., Blanco-Moreno, J.M. \& Sans, F.X. (2008) Increased fitness and plasticity of an invasive species in its introduced range: a study using Senecio pterophorus. Journal of Ecology, 96, 468-476.

di Castri, F. (1989) History of biological invasions with a special emphasis on the Old World. Biological Invasions: A Global Perspective (eds J.A. Drake, H.A. Mooney, F. di Castri, R.H. Groves, F.J. Kruger, M. Rejmanek \& M. Williamson), pp. 1-30. John Wiley \& Sons, Chichester.

Chun, Y. (2011) Phenotypic plasticity of introduced versus native purple loosestrife: univariate and multivariate reaction norm approaches. Biological Invasions, 13, 819-829.

Colautti, R.I., Eckert, C.G. \& Barrett, S.C.H. (2010) Evolutionary constraints on adaptive evolution during range expansion in an invasive plant. Proc $R$ Soc B, 277, 1799-1806

Colautti, R.I., Maron, J.L. \& Barrett, S.C.H. (2009) Common garden comparisons of native and introduced plant populations: Latitudinal clines can obscure evolutionary inferences. Evolutionary Applications, 2, 187-199.

DeWalt, S.J., Denslow, J.S. \& Ickes, K. (2004) Natural-enemy release facilitates habitat expansion of the invasive tropical shrub Clidemia hirta. Ecology, 85, 471-483.

Dlugosch, K.M. \& Parker, I.M. (2008) Founding events in species invasions: genetic variation, adaptive evolution, and the role of multiple introductions. Molecular Ecology, 17, 431-449.

Gaston, K.J. (2003) The Structure and Dynamics of Species Ranges. Oxford University Press, Oxford.

Griffith, T.M. \& Watson, M.A. (2005) Stress avoidance in a common annual reproductive timing is important for local adaptation and geographic distribution. Journal of Evolutionary Biology, 18, 1601-1612.

Grinnell, J. (1917) Field tests of theories concerning distributional control. Am Nat, 51, 115-128.

Heliyanto, B., Krauss, S.L., Lambers, H., Cawthray, G.R. \& Veneklaas, E.J (2006) Increased ecological amplitude through heterosis following wide outcrossing in Banksia ilicifolia R.Br. (Proteaceae). Journal of Evolutionary Biology, 19, 1327-1338

Hijmans, R.J., Cameron, S.E., Parra, J.L., Jones, P.G. \& Jarvis, A. (2005) Very high resolution interpolated climate surfaces for global land areas. International Journal of Climatology, 25, 1965-1978.

Hultén, E. \& Fries, M. (1986) Atlas of North European Vascular Plants North of the Tropic of Cancer. Koeltz Scientific Books, Königstein.

Hutchinson, G.E. (1957) Concluding remarks. Cold Spring Harbor Symp Quan Biol, 22, 415-427.

Joshi, J., Schmid, B., Caldeira, M.C., Dimitrakopoulos, P.G., Good, J., Harris, R. et al. (2001) Local adaptation enhances performance of common plant species. Ecological Letters, 4, 536-544.

Jump, A.S., Mátyás, C. \& Peñuelas, J. (2009) The altitude-for-latitude disparity in the range retractions of woody species. Trends in Ecology \& Evolution, 24, 694-701.

Keller, F.\& Körner, C. (2003) The role of photoperiodism in alpine plant development. Arctic, Antarctic, and Alpine Research, 35, 361-368.

Keller, S.R. \& Taylor, D.R. (2008) History, chance and adaptation during biological invasion: separating stochastic phenotypic evolution from response to selection. Ecological Letters, 11, 852-866.

Keller, S.R. \& Taylor, D.R. (2010) Genomic admixture increases fitness during a biological invasion. Journal of Evolutionary Biology, 23, 1720-1731.

Keller, S.R., Sowell, D.R., Neiman, M., Wolfe, L.M. \& Taylor, D.R. (2009) Adaptation and colonization history affect the evolution of clines in two introduced species. New Phytologist, 183, 678-690

van Kleunen, M. \& Fischer, M. (2008) Adaptive rather than non-adaptive evolution of Mimulus guttatus in its invasive range. Basic Appl Ecol, 9, 213-223.
Körner, C. (2007) The use of 'altitude' in ecological research. Trends in Ecology \& Evolution, 22, 569-574

Lacey, E.P. \& Herr, D. (2000) Parental effects in Plantago lanceolata L. III Measuring parental temperature effects in the field. Evolution, 54, 1207 1217.

Latta, R.G., Gardner, K.M. \& Johansen-Morris, A.D. (2007) Hybridization, recombination, and the genetic basis of fitness variation across en vironments in Avena barbata. Genetica, 129, 167-177.

Leger, E.A. \& Rice, K.J. (2007) Assessing the speed and predictability of local adaptation in invasive California poppies (Eschscholzia californica). Journa of Evolutionary Biology, 20, 1090-1103.

Monty, A. \& Mahy, G. (2009) Clinal differentiation during invasion: Senecio inaequidens (Asteraceae) along altitudinal gradients in Europe. Oecologia, 159, 305-315.

Normand, S., Treier, U.A., Randin, C., Vittoz, P., Guisan, A. \& Svenning, J.-C. (2009) Importance of abiotic stress as a range-limit determinant for European plants: insights from species responses to climatic gradients. Global Ecology and Biogeography, 18, 437-449.

Parker, I.M., Rodriguez, J. \& Loik, M.E. (2003) An evolutionary a pproach to understanding the biology of invasions: local adaptation and general-purpose genotypes in the weed Verbascum thapsus. Conservation Biology, 17 , 59-72.

Pearman, P.B., Guisan, A., Broennimann, O. \& Randin, C.F. (2008) Niche dynamics in space and time. Trends in Ecology \& Evolution, 23, 149-158.

Peterson, A.T. (2003) Predicting the geography of species' invasions via ecological niche modelling. Quarterly Review of Biology, 78, 419-433.

Peterson, A.T. (2011) Ecological niche conservatism: a time-structured review of evidence. Journal of Biogeography, 38, 817-827.

Pigott, C.D. (1981) Nature of seed sterility and natural regeneration of Tilia cordata near its northern limit in Finland. Amn Bot Fenn, 18, 255-263.

Pigott, C.D. \& Huntley, J.P. (1981) Factors controlling the distribution of Tilie cordata at the northern limits of its geographical range. III. Nature and causes of seed sterility. New Phytologist, 87, 817-839.

R Development Core Team (2010) R: A Language and Enviromment for Statistical Computing. R Foundation for Statistical Computing, Vienna, Austria

Reybould, A.F., Gray, A.J., Lawrence, M.J. \& Marshall, D.F. (1991) The evolution of Spartina anglica C.E. Hubbard (Gramineae): genetic variation and status of the parent species in Britain. Biological Journal of the Linnean Society, 44, 369-380.

Richards, C.L., Bossdorf, O., Muth, N.Z., Gurevitch, J. \& Pigliucci, M. (2006) Jack of all trades, master of some? On the role of phenotypic plasticity in plant invasions Ecological Letters, 9, 981-993.

Sagar, G.R. \& Harper, J.L. (1964) Plantago major L., P. media L. and $P$. lanceolata L. Journal of Ecology, 52, 189-221.

Teramura, A.H., Antonovics, J. \& Strain, B.R. (1981) Experimental ecological genetics in Plantago IV. Effects of temperature on growth rates and reproduction in three populations of Plantago lanceolata L. (Plantaginaceae). American Journal of Botany, 68, 425-434.

Theurillat, J.-P. \& Guisan, A. (2001) Potential impact of climate change on vegetation in the European Alps: a review. Clim Change, 50, 77-109.

van Tienderen, P.H. (1992) Variation in a population of Plantago lanceolata along a topographical gradient. Oikos, 64, 560-572.

van Tienderen, P.H. \& van der Toorn, J. (1991) Genetic differentiation between populations of Plantago lanceolata. I. Local adaptation in three contrasting habitats. Journal of Ecology, 79, 27-42.

Verhoeven, K.J.F., Macel, M., Wolfe, L.M. \& Biere, A. (2011) Population admixture, biological invasions and the balance between local adaptation and inbreeding depression. Proc $R$ Soc $B, \mathbf{2 7 8}, 2-8$.

Williams, J., Auge, H. \& Maron, J. (2008) Different gardens, different results: native and introduced populations exhibit contrasting phenotypes across common gardens. Oecologia, 157, 239-248.

Wolfe, L.M., Blair, A.C. \& Penna, B.M. (2007) Does intraspecific hybridization contribute to the evolution of invasiveness?: an experimental test. Biological Invasions, 9, 515-521 
Figure S1. Variation in monthly mean temperature at the five experimental sites.

Figure S2. Reaction norms for fitness parameters across sites shown individually for each native and introduced population.

Table S1. The locations and other attributes of the sampled populations.

Table S2. Results of model selection for the seven fitness traits.
Table S3. Results of model selection including alternative environmental explanatory variables (PCT2 and precipitation) for the seven fitness traits.

As a service to our authors and readers, this journal provides supporting information supplied by the authors. Such materials may be re-organized for online delivery, but are not copy-edited or typeset. Technical support issues arising from supporting information (other than missing files) should be addressed to the authors. 